\title{
The Influence of Mode on the Syntactic Complexity of EFL Students at Three Grade Levels
}

\author{
Margaret S.S. Yau and Joe Belanger
}

\begin{abstract}
This study extends the findings of syntactic research to students studying English as a foreign language. First, it corroborates earlier research findings on the relationships between syntactic complexity and grade level by examining a type of population not previously studied. Second, it extends earlier findings on the relation of mode and syntax to an English as a foreign language writing sample and examines the influence of the syntax in each mode of writing on the content of the compositions. In the expository mode, the upper-grade students used
\end{abstract}

more non-clausal embeddings than the lower-grade students did, structures which are interpreted as providing the opportunity to express more complex relationships. In the narrative mode, on the other hand, the upper-grade students used significantly more clausal embeddings than their junior counterparts which resulted in greater detail in the narrations of the former. The older students appeared to be more able to adjust their syntax to the demands of the rhetorical task than the younger students were.

By now the T-unit has been used with success in so many studies that its usefulness as a gauge of syntactic maturity of native speakers of English must be considered beyond question. O'Donnell (1976) suggests, “...in spite of lack of precision, T-unit length is still the most useful and usable index of syntactic development over a wide age-range..."(p.38). Studies of samples from many languages suggest that the $T$-unit transcends language boundaries, but evidence is still being accumulated on the value of the T-unit for languages other than English and for speakers of English as a foreign language. An additional question of interest is the part mode of writing plays in syntactic complexity measured by the T-unit.

Working with native speakers of non-Indo-European languages, Hunt (1977) reported that the writing of Japanese, Korean, Fijian, Indonesian, Laotian, and Marshallese children increased in syntactic complexity with age. Reesink et al. (1971) reported similar findings with Dutch students. Researchers examining students at an American university who were learning German (Cooper, 1976) and French (Monroe, 1975) found that syntactic complexity increased with the number of years the foreign language was studied. Larsen-Freeman and Strom (1977) and LarsenFreeman (1978) reported that the percentage of error-free T-units differentiated proficiency levels of ESL university students. 
Researchers have also found that differences in syntactic complexity which are related to mode of writing are crucial to interpreting any research dealing with clause and sentence length factors. Studies of native speakers of English (Rosen, 1969; San José, 1972; Perron, 1976; Crowhurst and Piche, 1979; Crowhurst, 1980a) have shown that mode exerts an important influence on syntactic factors such as T-unit length, clause length, and number of clauses per T-unit. The study reported below extends these findings to students whose native language is not Indo-European and who are learning English as a foreign language $\left(\mathrm{EFL}^{1}\right)$.

\section{PROCEDURES}

Sixty subjects were randomly chosen from a secondary school in Hong Kong, 20 each from Forms 3, 5, and 7 (roughly equivalent to grades 9, 11, and 13 in North America). The students each wrote two compositions on assigned topics (one eliciting narrative writing and the other expository writing) under controlled conditions. During the week before the compositions were written, a uniform series of prewriting procedures was used at each grade level to ensure that generation of content and ideas would not impede the students' syntactic performance.

Three syntactic measures-words per T-unit ${ }^{2}$ (W/TU), words per clause (W/CL), and clauses per T-unit (CL/TU) - were analyzed by three separate analyses of variance in a 3 (grade) by 2 (mode) factorial design with a repeated measure on the second factor. Bonferroni $t$-statistics were used for the pairwise comparisons within one mode across the three grades and $t$-tests for correlated measures were used for the pairwise comparisons between the two modes of writing within each grade level.

\section{RESULTS}

Analysis of clause and sentence length factors in the compositions of these EFL students yielded results very similar to those that would be expected extrapolating from research with native speakers of English.

Although all syntactic factors showed more complexity in the expository mode than in the narrative mode, the students wrote longer narrative compositions than expository compositions. The average number of words written by the students ranged from 201 words at Form 3 to 238.4 words at Form 7 in the narrative assignment and 186.8 words at Form 3 and 229.3 at Form 7 in the expository assignment.

Compositions written at each higher grade level were more syntactically complex. This trend was significant for $\mathrm{W} / \mathrm{TU}, \mathrm{F}(2,57)=17.97$, $\mathrm{p}<.0001$; $\mathrm{W} / \mathrm{CL}, \mathrm{F}(2,57)=11.41, \mathrm{p}<.0001 ;$ and $\mathrm{CL} / \mathrm{TU}, \mathrm{F}(2,57)=15.93,<.0046$. 
Compositions written on the expository assignment were also more syntactically complex than those written on the narrative assignment. This trend was significant both for $\mathrm{W} / \mathrm{TU}, \mathrm{F}(1,57)=76.79, \mathrm{p}<.0001$ and $\mathrm{W} / \mathrm{CL}, \mathrm{F}(1,57)=55.74, \mathrm{p}<.0001$. It approached significance for $\mathrm{CL} / \mathrm{TU}$, $\mathrm{F}(1,57)=5.93, \mathrm{p}<.0651$.

There was a significant interaction between grade and mode for $\mathrm{W} / \mathrm{TU}$, $F(2,57)=3.39, p<.0406$ and $W / C L, F(2,57)=6.39, p<.0031$. Subsequent grade-wise comparisons in each separate mode of writing indicated that this interaction could be accounted for by the fact that the Form 7 students showed a good deal more complexity on the expository assignment than on the narrative assignment, but the Form 3 students did not follow this pattern. Bonferroni t-statistics and $t$-tests for correlated measures revealed the following:

Table 1

Mean Differences between Grade Levels and Statistical Decisions based on Bonferroni t-Statistics on the Narrative and Expository Assignments

Measures

Grade W/TU W/CL $\quad$ CL/TU

$\begin{array}{llllll}\mathbf{d} & \mathbf{p} & \mathbf{d} & \mathbf{p} & \mathbf{d} & \mathbf{p}\end{array}$

Narrative Assignment

$\begin{array}{llclllc}\text { F.3-F.5 } & 1.00 & \text { NS } & 0.03 & \text { NS } & 0.12 & \text { NS } \\ \text { F.5-F.7 } & 1.48 & <.05 & 0.38 & \text { NS } & 0.14 & <.05 \\ \text { F.3-F.7 } & 2.48 & <.01 & 0.41 & \text { NS } & 0.26 & <.01\end{array}$

Expository Assignment

\begin{tabular}{lllllll} 
F.3-F.5 & 1.67 & NS & 0.94 & NS & 0.05 & NS \\
F.5-F.7 & 2.93 & $<.01$ & 1.53 & $<.05$ & 0.07 & NS \\
F.3-F.7 & 4.60 & $<.01$ & 2.47 & $<.01$ & 0.12 & NS \\
\hline
\end{tabular}


1. As Table 1 shows, on the narrative assignment there was a significant difference across grade levels in W/TU and CL/TU between Forms 3 and 7 and Forms 5 and 7, but not Forms 3 and 5. In W/CL, however, there was no significant difference between any two grades. In fact, an examination of the raw scores for the latter measure revealed that there was almost no increase in the number of words per clause with succeeding grade levels.

2. On the expository assignment, there was a significant difference across grade levels in W/TU and W/CL between Forms 3 and 7 and Forms 5 and 7, but not Forms 3 and 5. In CL/TU, however, there was no significant difference between any two grades.

Table 2

Mean T-Unit Length, Mean Clause Length, and Mean Number of Clauses per T-Unit Written by Students at Three Grade Levels and in Two Modes of Writing with Statistical Decisions Based on t-Tests

\begin{tabular}{|c|c|c|c|c|c|c|c|}
\hline & \multicolumn{5}{|c|}{ Mode } & \multirow[b]{3}{*}{ t-value } & \multirow[b]{3}{*}{$\mathbf{p}$} \\
\hline & \multicolumn{3}{|c|}{ Narrative } & \multicolumn{2}{|c|}{ Expository } & & \\
\hline \multicolumn{6}{|l|}{ Measure } & & \\
\hline \multirow[t]{3}{*}{$\mathrm{W} / \mathrm{TU}$} & F. 3 & 9.00 & 1.49 & 11.04 & 2.06 & 4.65 & $<.0005$ \\
\hline & F. 5 & 10.00 & 1.67 & 12.71 & 2.41 & 5.40 & $<.0005$ \\
\hline & F.7 & 11.48 & 1.92 & 15.64 & 3.61 & 5.41 & $<.0005$ \\
\hline \multirow[t]{3}{*}{$\mathrm{W} / \mathrm{CL}$} & F.3 & 7.16 & 1.07 & 7.93 & 1.30 & 2.18 & $<.025$ \\
\hline & F. 5 & 7.19 & 0.71 & 8.87 & 1.78 & 3.96 & $<.0005$ \\
\hline & F.7 & 7.57 & 0.93 & 10.40 & 1.80 & 6.42 & $<.0005$ \\
\hline \multirow[t]{3}{*}{$\mathrm{CL} / \mathrm{TU}$} & F. 3 & 1.26 & 0.16 & 1.40 & 0.18 & 2.59 & $<.01$ \\
\hline & F.5 & 1.38 & 0.14 & $<1.45$ & 0.27 & 1.12 & NS \\
\hline & F.7 & 1.52 & 0.19 & $<1.52$ & 0.33 & 0.00 & NS \\
\hline
\end{tabular}


3. As Table 2 shows, when the narrative and expository modes were compared, there was a significant difference in $\mathrm{W} / \mathrm{TU}$ and $\mathrm{W} / \mathrm{CL}$ at all three grade levels. In W/CL the difference between modes was progressively greater with each higher grade. In CL/TU, however, a significant difference between modes was found only in the Form 3 writing. An examination of the raw scores (Table 2) reveals that the difference between modes on the number of clauses per T-unit diminishes with grade levels, until at Form 7, there is practically no difference.

\section{DISCUSSION}

This study corroborates the findings of previous research which show that increases in syntactic complexity are related to the age or grade levels of the subjects (as in Hunt, 1965; O'Donnell, Griffin \& Norris, 1967) or in the case of second language learners, to increased experience in learning the second language (e.g., Thornhill, 1969; Monroe, 1975; Cooper, 1976; Larsen-Freeman and Strom, 1977; Larsen-Freeman, 1978). This agerelated increase is discussed in detail in Yau (1983).

This study also extends the findings of researchers such as San José (1972), Perron (1976), Crowhurst and Piche (1979), Crowhurst (1980a) who noted that mode of writing exerts a significant influence on syntactic complextity. In this study, the EFL students at all three grade levels produced T-units and clauses that were more syntactically complex on the expository assignment than on the narrative assignment. These differences were statistically significant at all three grades.

Crowhurst and Piche (1979) made the observation that mode may exert a greater influence on syntactic complexity than grade level does. In the current study, when the raw scores for two modes combined are compared, there is a difference of about 3.5 words in T-unit length between Form 3 and Form 7 . When the raw scores on the narrative and expository assignments are compared at Form 7 , there is a difference of 4 words between the two assignments. With these EFL students, then, the differences between the two modes are greater than the differences related to a five-year age span.

The study also corroborates the suggestion that the expository mode of writing makes more demands on the writers' syntactic resources than the narrative mode of writing does. In narration especially, students tend to reach their maximum complexity early. For example, Crowhurst and Piche (1979) found no significant differences on any of the syntactic measures between the narrations of grade 6 and 10 students while Crowhurst (1980a) found a significant difference in T-unit length between the narrations of grade 6 and 10 students but not between grade 10 and 12 
students. The current study found a non-significant increase in clause length between the narrations of Forms 3 and 7; however, there was a significant increase in T-unit length and in the number of clauses per T-unit. In the argumentative assignment, Crowhurst and Piche (1979) found a significant difference between grades 6 and 10 on all three measures. There was also a significant difference in $T$-unit length across the three grades in argumentation in the later Crowhurst (1980a) study. The current study found a significant increase in T-unit length and clause length with grade levels in the expository assignment, but the increase in the number of clauses per T-unit was not statistically significant.

In the current study, the non-significant difference in CL/TU can be explained by examining the grammatical transformations that the Form 3 and Form 7 students used to expand their T-units. Grammatical analysis (Yau, 1983) indicated that the Form 7 students made use of a greater variety of ways to express the interrelationships between propositions than the Form 3 students did. Non-clausal embedding and the use of sentence connectors were the two strategies that most distinguished the Form 3 and from the Form 7 writing. The expository mode of writing requires writers to link propostions in logical ways. To do this, the Form 3 students relied heavily on subordination while the Form 7 students augmented subordination with the use of non-clausal embedding and sentence connectors. For example,

Form 3: Peter failed because he was lazy.

Form 7: Peter failed because of laziness.

Had the Form 7 students relied more heavily on clausal embedding, there might well have been a significant difference in clauses per T-unit between Form 3 and Form 7.This would have brought the finding of the current study in line with those of Crowhurst and Crowhurst and Piche.

With the variation in clauses per T-unit explained, the three studies generally agree that age-related increases on the syntactic measures may stop at a certain point in the narrative mode and that beyond this point development in syntactic complexity may be better reflected in the argumentative or expository mode of writing. In the current study, it is interesting that although the native language of these students (Chinese) is very different from the target language (English), the effects of mode on their English writing are similar to the effects of mode on the writing of students whose native language is English.

An examination of the compositions written by the Form 3 and 7 students suggests that the ability to adjust the complexity of syntax in response to different writing tasks is related to the students' experience in using the second language. This suggestion is supported by comparing the 
different ways the two groups used to expand their T-units in the expository and narrative assignment. The T-units written by the Form 7 students were significantly longer than the T-units written by the Form 3 students in both modes of writing. However, the longer T-units produced by the Form 7 students were lengthened very differently in the two modes of writing.

On the narrative assignment, while the Form 7 students did not write significantly longer clauses than the Form 3 students did, they embedded a significantly greater number of subordinate clauses into their T-units. The Form 3 students, on the other hand, employed a low level of clause embedding (mean score on this variable for Form 3 was 1.26, compared to 1.52 for Form 7). The Form 3 students generally used clauses of time while the Form 7 students used a higher proportion of noun clauses, relative clauses, and adverbial clauses other than time (reason, concession, comparison, and result, for example). Mellon (1979) suggests that subordination is a syntactic device which adds secondary statements to main clauses. If this is the case, the employment of this syntactic device would serve to add more details to the Form 7 narrations. A subjective examination of the sample confirmed that the Form 7 narrations made more use of detail than the Form 3 narrations did.

On the expository assignment, the Form 7 students made use of significantly longer clauses than the Form 3 students did. Inasmuch as Hunt's procedures for counting clause length preclude the expansion of average clause length by clausal embedding, these longer clauses must result from non-clausal embedding. These non-clausal embeddings are made by deletion transformations which result in compressed thought units (cf., Hunt, 1970). Therefore, the longer clauses of the Form 7 students should contain more complex thoughts than those in the Form 3 writing. Such a conclusion is supported by a subjective comparison of the complexity of thought in the compositions of the Form 3 and Form 7 students. Whether this complexity of thought is the result of the more complex syntax or the complex syntax is the result of complex thought remains to be investigated. Study of such questions may yield important information about cognition and writing.

It is also worth examining the shorter average clause length of the Form 3 expositions. The clauses written by the Form 3 students on the expository assignment were, on the average, 2.47 words shorter than the clauses written by the Form 7 students. Two plausible explanations for the relatively shorter clauses produced by the Form 3 students are the students' lack of familiarity with the expository mode of writing and their lack of fluency in syntactic manipulation. An examination of the Form 3 expositions suggested that many of the Form 3 students turned the exposition into a kind of narrative description. Even those who attempted 
to write an exposition made use of a substantial number of narrative details as support for their expositions. Being inexperienced writers (free writing in English starts at the Form 3 level in the school where the current study was conducted), these Form 3 students may not have had so much practice in the expository mode as they had in the narrative mode. (This explanation is in accord with the intuition of teachers of beginning writers: Crowhurst (1980b) reported that Grade 6 teachers did not often ask their students to write in the argumentative or expository mode.) Their lack of familiarity with the expository mode of writing may then explain why the Form 3 students depended on narrative details as support for their expositions. Since narration does not usually entail a high level of syntactic complexity, the narrative details that these students used in their expositions may partly account for the shorter clause length of their expositions.

A second explanation for the shorter clauses written by the Form 3 students is their lack of fluency in syntactic manipulation or lack of fluency in writing in general. Being unsophisticated users of the second language and unskilled writers (compared to the Form 7 students), their poor abilities in English might constrain them from attending to the rhetorical tasks in the way that the Form 7 students do. Bereiter (1980) suggests:

\begin{abstract}
Mature writing involves a large number of skills at different processing levels. Adequate mature functioning can be possible only when many of the skills are highly automated and when they are well enough coordinated to permit efficient time-sharing. Neither of these conditions is met in the young writer, and so the young writer, in order to function at all, must employ a structurally simplest system that does not require so much simultaneous and coordinated functioning. Since low-order schemes-those involved in getting words on to paper-must take priority in order for writing to occur, it follows that the system employed by the young writer must be one in which low-order schemes predominate and higher order schemes play a lesser part...(p.82).
\end{abstract}

Attention to such low-order schemes results in a kind of "associative writing" which "consists essentially of writing down whatever comes to mind, in the order in which it comes to mind" (Bereiter, 1980, p.83). Whether the Form 3 students produced such associative writing remains to be investigated, but Bereiter's suggestion may partly explain the narrative details and, in general, the shorter clauses found in the Form 3 expositions. Narration does not require the kind of abstraction that exposition or argumentation entails and is therefore the least cognitively demanding of the three to process (cf., Winterowd, 1983). 
Shorter clauses are also less cognitively straining to process (Kerek, 1981). Since the Form 3 students were not fluent in the second language, the difficulty they experienced in writing an exposition in English (a demanding mode of writing even for native English speaking students) may have focused their attention on the lower-order schemes described by Bereiter which, in turn, may have caused them to opt for rhetorical devices that made the least demand on them. This may partly account for the fact that they wrote less complex syntax and employed more narrative details in their expositions.

\section{IMPLICATIONS}

The current study provides some informal evidence that the ability to adjust syntactic complexity to the writing task shows a developmental trend. The increased differentiation of the syntactic structures between the two modes of writing exhibited by the upper-grade students provides one such indication. The above discussion also suggests that these differentiations enable the upper-grade students to conform better to the rhetorical demands of the writing task. The population used in this study and relationships between grade level and mode of writing suggest a number of profitable investigations:

1.What are the relationships among mode of writing, grade levels, and the syntactic structures taught in a sentence combining program? For example, this study suggests that a given mode of writing may require more fluency in one syntactic structure than in another. For example, exposition appears to require more non-clausal embeddings than clausal embeddings. Form 3 students tend to be more at ease with the latter than the former, which appears to impair their expositions. Researchers, then, must specify the structures which are to be taught at a specific level to enhance a given target mode. In addition, the mode of writing used to measure the results of the program must be compatible with the structures being taught.

2. It seems self-evident that there is a close relationship between complexity of thought and complexity of language. Obviously, it is difficult for simple syntax to carry the complex thought of exposition and argumentation. However, it is not clear whether helping students to generate ideas will lead them to produce more complex sentence structures (one of the assumptions of recent work on the writing process) or if teaching them complex syntax will help them to generate more complex thoughts (the premise of Francis Chistensen's (1963) generative thetoric of the sentence). The EFL students who were the subjects of the current study are 
ideal subjects to use to investigate this question because researchers can assume that the structures used are those learned in school: the students do not use English outside the classroom. Consequently, if the nonclausal embeddings found to distinguish between the expositions of the Form 3 and Form 7 students in the current study were hypothesized to generate thought, experimental groups could be taught this feature while control groups were not. Differences in the thought complexity of compositions following the experiment could then be attributed only to the treatment. Such an experiment could not be carried out with native speakers because of the possibility of contamination from sources outside the experiment. Indeed, native speakers would likely have been familiar with the structures long before they reached high school.

3. What part does the linguistic ability of the writers play in composition? Bereiter (1980) suggests that young writers pay such close attention to the lower-order schemes of writing that they cannot attend to the rhetorical demands of the writing task. Since Bereiter was using native English speakers as examples, the young writers that he referred to must be both cognitively immature and linguistically immature. It would be interesting to investigate how writers at a mature level of cognitive ability but immature linguistic ability react to the writing task. Such investigations would shed light on the relationships among cognitive abilities, linguistic abilities, and writing skill.

\section{FOOTNOTES}

${ }^{1}$ English as a foreign language (EFL) differs from English as a second language (ESL) in that the EFL students are not immersed in the culture of the new language, generally using English in classroom-related activities only.

${ }^{2}$ Following Hunt (1970), a T-unit was defined as one main clause plus any subordinate clauses or non-clausal elements attached to or embedded in it. Again, following Hunt (1970), "The criterion used to decide whether a certain expression was to be counted as a clause was the same as that which appears in most schoolbook grammars: the expression must contain a subject (or coordinated subjects) and must contain a finite verb (or coordinated verbs)" (pp. 13-14).

Before each composition was segmented into T-units, extraneous matter called "garble" was defined as any sentence, or part of a sentence, that was unintelligible. Sentence fragments which resulted from non-standard usage (e.g., wrong punctuation, misused parts of speech, wrong prepositions, omissions, etc.) were retained so long as their semantic contents were clear. 


\section{REFERENCES}

Bereiter, C. (1980). Development in writing. In Gregg, L.W., \& Steinberg, E.R. (Eds.). Cognitive processes in writing. Hillsdale, N.J.: Lawrence Erlbaum Associates.

Christensen, F. (1963). A generative rhetoric of the sentence. College Composition and Communication, 14 155-161.

Cooper, T.C. (1976). Measuring written syntactic patterns of second language learners of German. Journal of Educational Research, 69, 176-183.

Crowhurst, M. (1980a). Syntactic complexity in narration and argument at three grade levels. Canadian Journal of Education, 5, 6-12.

Crowhurst, M. (1980b). Syntactic complexity and teachers' quality ratings of narrations and arguments. Research in the Teaching of English, 14(3), 223-231.

Crowhurst, M., \& Piche, G.L. (1979) Audience and mode of discourse effects on syntactic complexity in writing at two grade levels. Research in the Teaching of English, 13, 101-109.

Hunt, K.W. (1965). Grammatical structures written at three grade levels. Research Report No. 3 Urbana, Ill.: NCTE.

Hunt, K.W. (1970). Syntactic maturity in school-children and adults. Monographs of the Society for Research in Child Development, 35.

Hunt, K.W. (1977). Early blooming and late blooming syntactic structures. In C.R. Cooper \& L. Odell (Eds.), Evaluating writing. Urbana, Ill.: NCTE.

Kerek, A. (1981). The combining process. In M.C. Hairston \& C.L. Selfe (Eds.), Selected papers from the 1981 Texas Writing Research Conference. (Austin, Texas, Aug. 1981) (ERIC Document Reproduction Service No. ED 208 417).

Larsen-Freeman, D. (1978). An ESL index of development. TESOL Quarterly, 12, 439-450.

Larsen-Freeman, D., \& Strom, V. (1977). The construction of a second language acquisition index of development. Language Learning, 27, 123-134.

Mellon, J.C. (1979). Issues in the theory and practice of sentence combining: A twenty-year perspective. In D.A. Daiker, A. Kerek, \& M. Morenberg (Eds.), Sentence combining and the teaching of writing. Ohio: University of Akron.

Monroe, J.H. (1975). Measuring and enhancing syntactic fluency in French. French Review, 48, 1023-1031.

O'Donnell, R.C. (1976). A critique of some indices of syntactic maturity. Research in the Teaching of English, 10, 31-38.

O'Donnell, R.C., Griffin, W.J., \& Norris, R.C. (1967). Syntax of kindergarten and elementary school children. Research Report No. 8. Urbana, Ill:: NCTE.

Perron, J.D. (1976). The impact of mode on written syntactic complexity. Part III. Fifth grade. Studies in Language Education, Report No. 27. Department of Language Education, The University of Georgia (ERIC Document Reproduction Service No. ED 128 827).

Reesink, G.P., Holleman-van der Sleen, S.B., Stevens, K., \& Kohnstumm, G.A. (1971). Development of syntax among school children and adults: A replication investigation. Psychological Abstracts, 47, 105-136.

Rosen, H. (1969). An investigation of the effects of differentiated writing assignments on the performance in English composition of a selected group of 15/16-year-old pupils. Unpublished Ph.D. thesis, University of London. 
San José, C.P.M. (1972). Grammatical structures in four modes of writing at fourth grade level. Unpublished Doctoral Dissertation, Syracuse University.

Thornhill, D.E. (1969). A quantitative analysis of syntactic fluency of four young adult speakers learning English. Unpublished Ph.D. Thesis, Florida State University.

Winterowd, W.R. (1983). Prolegomenon to pedagogical stylistics. College Composition and Communication, 34, 80-90.

Yau, M. (1983). Syntactic development in the writing of ESL students. Unpublished M.A. thesis, University of British Columbia.

\section{THE AUTHORS}

Margaret S.S. Yau is a doctoral student at the Ontario Institute for Studies in Education and Joe Belanger is an Assistant Professor at the University of British Columbia. The research reported here was partially funded by the Canadian Commonwealth Scholarship and Fellowship Committee. 